\title{
SEROTONIN RELEASE FROM CARCINOID TUMOURS
}

\author{
W. P. G. JoneS, M.B., CH.B.*
}

IN RECENT YEARS a peculiar syndrome associated with metastatic carcinoid tumours has been recognized and reported with increasing frequency. It is now apparent that this "Malignant Carcinoid Syndrome" is not as rare as was originally supposed. With increasing awareness of the existence of the disease it has instead become merely rather uncommon.

Although affected patients may exhibit varying clinical pictures, the classical, fully developed, syndrome always manifests many, if not all, the following salient features ${ }^{1}$ :

(1) Colicky abdominal pain, borborygmi, hypermotility of the bowel, and watery diarrhoea.

(2) Intermittent flushing of the skin, patchy cyanosis, permanent hyperaemia, and telangiectasia.

(3) Right-sided endocardial fibrosis, often associated with pulmonic stenosis, and tricuspid regurgitation.

(4) "Asthmatic-like" attacks with intermittent stridor, hyperpnoea, and sighing respiration.

(5) Miscellaneous findings including tissue oedema, ascites, pleural effusion, hypoalbuminaemia, dermatitis, arthraligia, and transient swelling of the face and hands.

In the great majority of cases with the syndrome the primary carcinoid tumour arises in the terminal ileum and is associated with extensive hepatic metastases. Tumour extracts and the blood of patients with the syndrome contain increased amounts of the hormone serotonin ${ }^{2}$ (5-hydroxytryptamine) and it is now accepted that many of the manifestations of the disease are the result of the excessive production of this substance by the tumour cells and its release into the circulation.

Considering the profound systemic effects of some other endocrine tumours such as the phaeochromocytoma, it is hardly surprising that the somewhat similar, biologically active, serotonin-elaborating, carcinoid tumour can produce marked derangement of many important physiological systems. Since many of these patients require operative procedures, these disturbing effects of excess circulating serotonin merit close study by the anaesthetist.

With some patients the course of anaesthesia may be uneventful. In others, however, alarming and occasionally fatal changes affecting cardiovascular and respiratory function can occur with dramatic suddenness. In this paper only the deleterious effects of hyperserotoninaemia on the heart and circulation will be considered.

"Department of Anesthesiology, St. Francis Hospital, Milwaukee, Wisconsin. 


\section{Cutaneous Flushing}

One of the most characteristic features of the syndrome is the intermittent, darkish red, cutaneous flush, the result of serotonin-induced arteriolar and capillary dilatation of the skin vessels. ${ }^{3}$ Usually flushing first affects the face and chest, but, as the disease progresses, it may spread to involve the hands, feet, and occasionally the whole body.

Flushing may occur during the induction of anaesthesia and in the course of operation. Important precipitating factors are fear and anxiety, episodes of hypotension, and palpation of the tumour and metastases.

However, cutaneous flushing is merely the outward and visible manifestation of complex haemodynamic changes involving the whole cardiovascular system. For example, during laparotomy flushing of the peritoneum and intestine has been observed. ${ }^{4}$ Similar changes have also been noted in the retinal vessels during cutaneous flushing. ${ }^{5}$

Thorson, ${ }^{4}$ in a detailed study of the circulatory changes during flushing in four patients with the carcinoid syndrome, described three definite stages during the development of a typical flush. Stage I, the beginning of the flush with reddening of the skin, lasts about 20 seconds. Stage II, when the flush is fully developed, usually lasts about 2 minutes, while Stage III, characterized by a patchy cyanosis, is often prolonged for several minutes. The clinical findings and their haemodynamic interpretation are shown in Table I. An interesting finding in this study was that the typical haemodynamic changes could occur in the absence of visible cutaneous flushing.

\section{TABLE I}

Circulatory Changes during Flushing (after Thorson)

\begin{tabular}{c}
\hline Stage I-Beginning of flush \\
Pulmonary vasoconstriction \\
Cutaneous vasodilatation \\
Low cardiac output \\
Falling peripheral resistance \\
Stage Il-Fully developed flush \\
Palpitation and tachycardia \\
Rise in systolic blood pressure \\
Increase in pulse pressure \\
High cardiac output \\
Low peripheral resistance \\
Stage III-Blanching or patchy cyanosis \\
Low cardiac output \\
Increased peripheral resistance \\
Blood pressure variable \\
Pulse pressure low
\end{tabular}

In the above investigation, despite the pronounced ballistocardiographic changes recorded during the various stages, there was no evidence of circulatory decompensation and the systemic blood pressure was maintained within fairly normal limits. These results are at variance with certain observed effects in anaesthetized patients undergoing surgery, during the course of which profound and sometimes persistent episodes of hypotension have been reported., ${ }^{4,6,7}$. In occa- 
sional cases hypotension has persisted for several hours after the completion of surgery. 8,9

However, in conscious patients, the profound haemodynamic changes produced during flushing are usually rapidly compensated by various circulatory reflexes so that only minor and transient changes in systemic blood pressure are observed. Under general anaesthesia the efficiency of these compensatory mechanisms may become compromised ${ }^{10}$ so that hypotension occurs.

\section{Circulatory Changes during Anaesthesia}

Table II is an analysis of the anaesthetic techniques used in a small series of 11 operations performed at the Cleveland Clinic on patients with the carcinoid syndrome.

TABLE II

Anaesthetic Technique and Blood Pressure Changes

\begin{tabular}{lccccc}
\hline \hline $\begin{array}{l}\text { Anaesthetic } \\
\text { technique }\end{array}$ & $\begin{array}{c}\text { No. of } \\
\text { cases }\end{array}$ & Rise & Fall & Biphasic & None \\
\hline $\begin{array}{l}\text { Spinal } \\
\text { Pent., } \mathrm{N}_{2} \mathrm{O},\end{array}$ & 4 & & + & & \\
$\begin{array}{l}\text { succinylcholine } \\
\text { Pent., } \mathrm{N}_{2} \mathrm{O} \text {, curare }\end{array}$ & 4 & 1 & 2 & & 2 \\
Pent., cyclo., curare & 2 & & 1 & 1 & \\
\hline
\end{tabular}

Hypotensive episodes were observed in all four cases given spinal anaesthesia and in three out of seven cases given general anaesthesia. The hypotension associated with spinal anaesthesia was more severe and prolonged than with general anaesthesia, necessitating a vasopressor for its reversal. Biphasic pressordepressor responses during handling of the tumour were seen in two cases under general anaesthesia.

Typical blood pressure readings recorded during anaesthesia and operation are shown in Figures 1, 2, and 3. Figures 1 and 2 show two different responses obtained in the same patient in two separate operative procedures. Figure 1 illustrates the blood pressures recorded during an exploratory laparotomy under continuous spinal anaesthesia, which disclosed a carcinoid tumour of the ileum with extensive liver metastases. Moderate hypotension followed injection of the spinal anaesthetic, and it was succeeded by a further precipitous fall in blood pressure during abdominal exploration.

This is interpreted as due to a failure of the circulation to adjust to the effects of serotonin released during the initial hypotension and by palpation of the tumour. The problem is further discussed in the next section.

At a later date a further operation became necessary for the relief of intestinal obstruction caused by the tumour mass. Anaesthesia was induced with a sleep dose of Pentothal and maintained with cyclopropane and oxygen. Following induction of anaesthesia, cutaneous flushing and a sharp rise in systolic blood pressure were observed. A steep fall in both systolic and diastolic pressure 
W. P. G. JONES: SEROTONIN RELEASE FROM CARCINOID TUMOURS

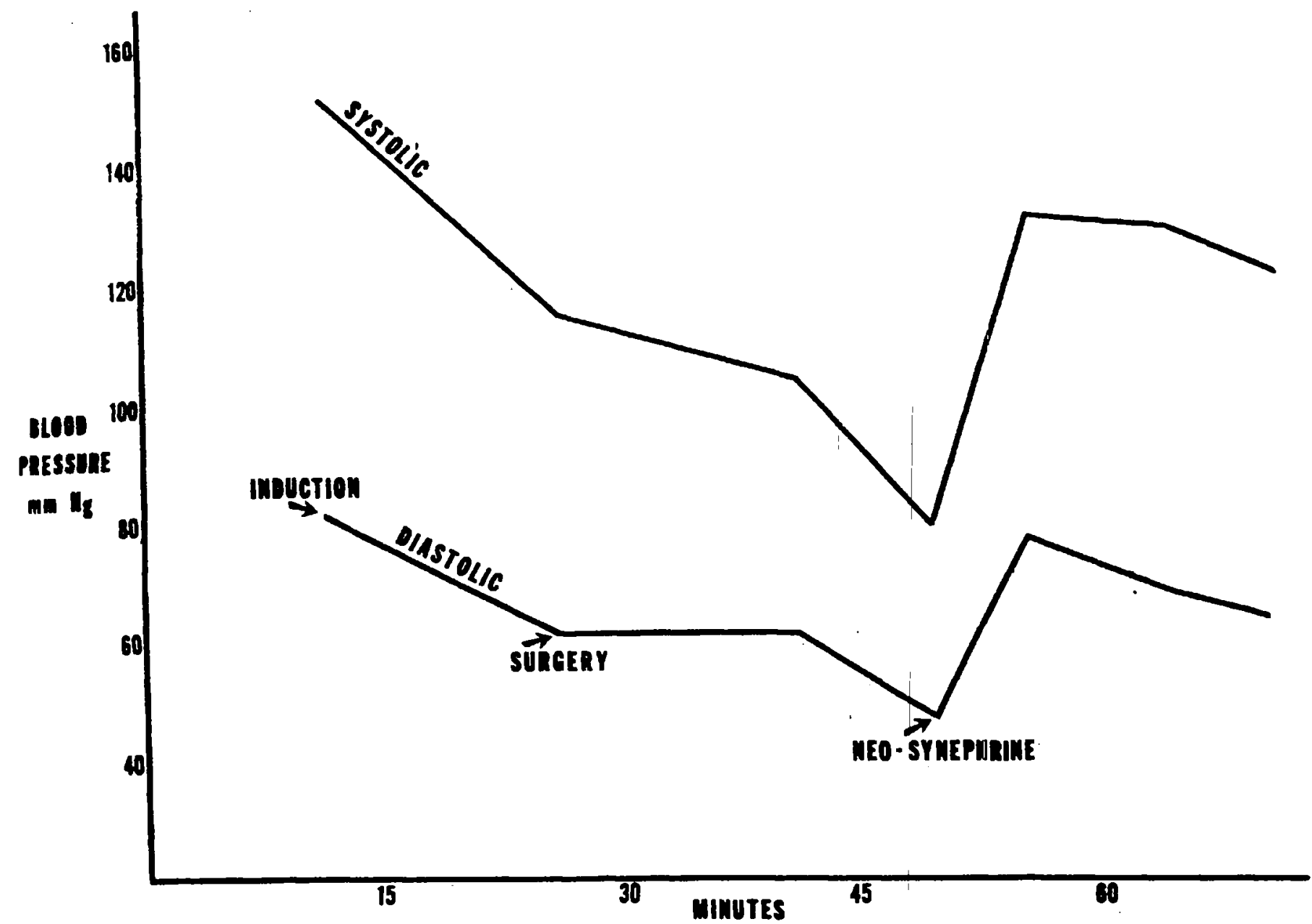

Frgure 1. Exploratory laparotomy under spinal anaesthesia.

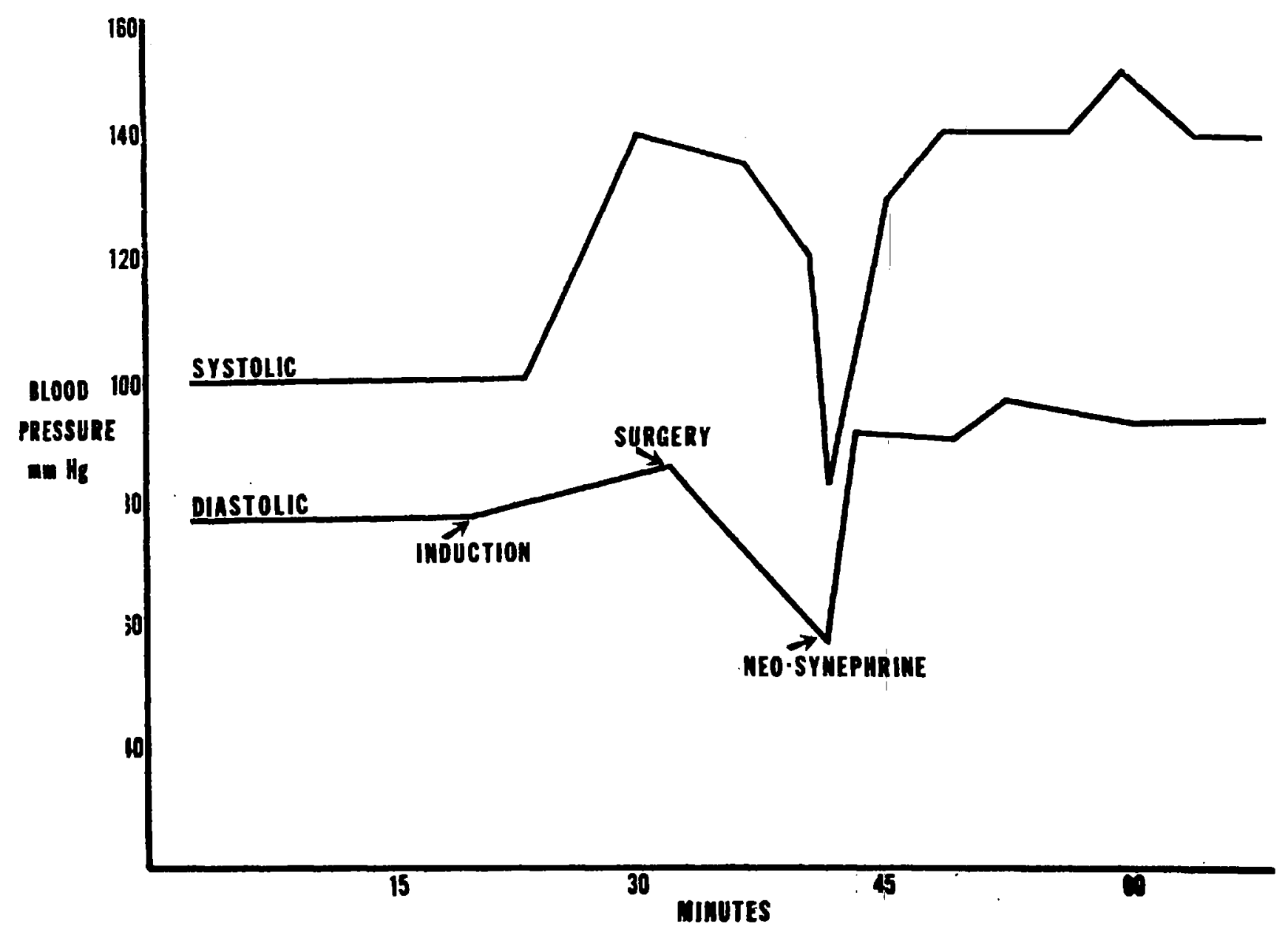

Figure 2. Lapàrotomy for intestinal obstruction under general anaesthesia: 


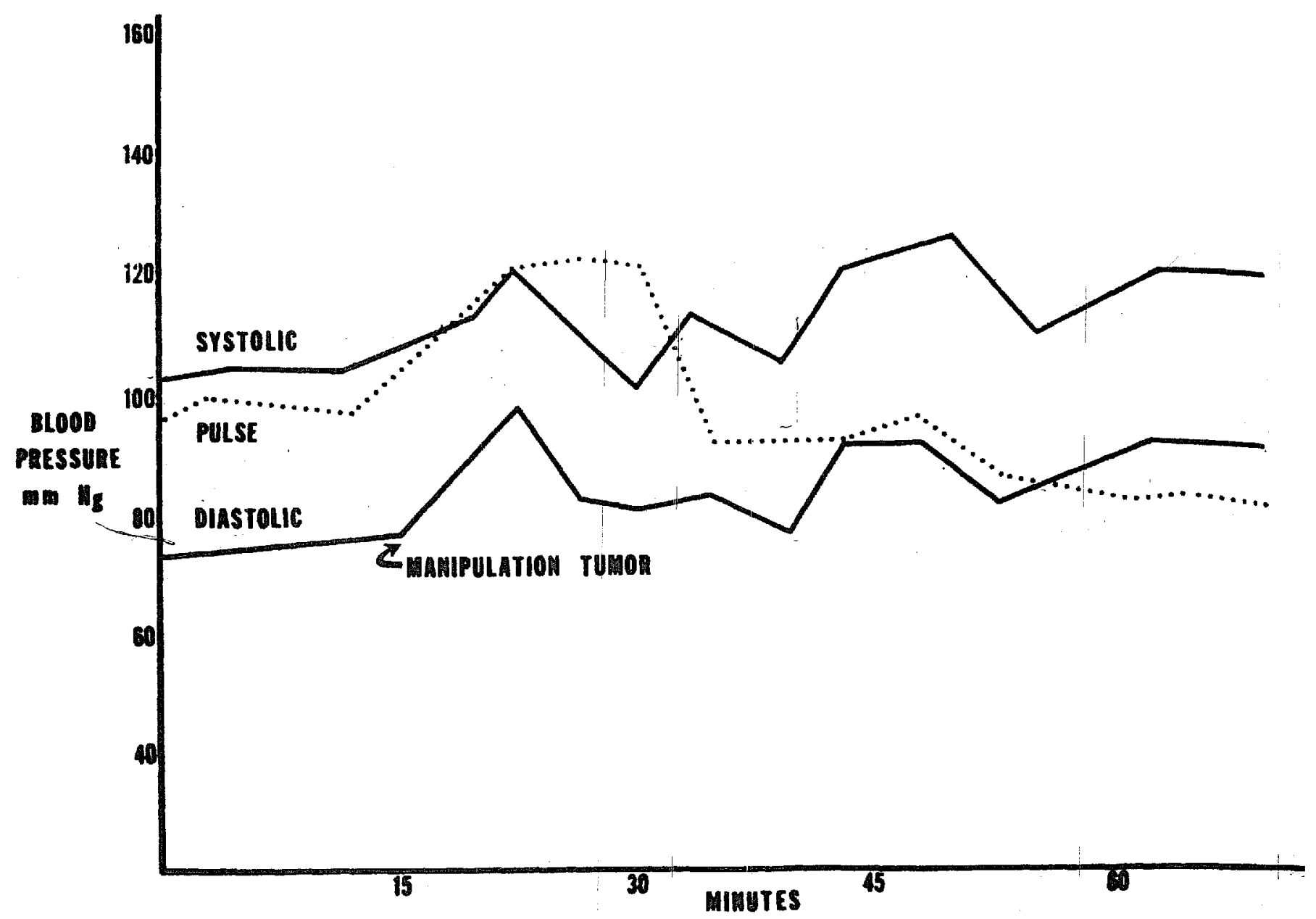

Figure 3. Carcinoid tumour of lung under general anaesthesia.

occurred during exploration of the abdomen. The above sequence of events is interpreted as an initial compensated response to serotonin released during the induction of anaesthesia. This would correspond to Stage II as described by Thorson. Later circulatory decompensation took place following the sudden release of further amounts of serotonin during palpation of the tumour and metastases.

Figure 3 illustrates a mild pressor response with tachycardia during manipulation of a carcinoid tumour of the lung under general anaesthesia. Circulatory adjustment is rapid with little change in systemic blood pressure.

\section{Deleterious Effect of Spinal Anaesthesia}

Though the number of cases studied is small, it would appear that spinal anaesthesia is contraindicated in patients with the carcinoid syndrome. To try to explain this deleterious effect of spinal anaesthesia the following hypothesis is advanced.

The carcinoid tumour cells are stimulated to release serotonin into the circulation by the hypotension following administration of the spinal anaesthetic or during handling of the tumour mass. High concentrations of serotonin thus reach the heart and pass through the right ventricle into the pulmonary circulation. The serotonin produces vasoconstriction in the pulmonary vascular bed ${ }^{11,12}$ leading to a transient fall in cardiac output and distention of the right ventricle. 
Some serotonin passes through into the systemic circulation and initiates the cutaneous flush (Stage I of Thorson).

The normal heart easily overcomes this obstruction to flow in the pulmonary circulation by a number of compensatory mechanisms. These include increased force of contraction of the right ventricular muscle (Starling's Law) and increase in the heart rate, ${ }^{13}$ so that systemic blood pressure is maintained. Further amounts of serotonin thus reach the skin and the flush becomes fully developed (Thorson's Stage II).

Experimental work on dogs by Guyton and co-workers ${ }^{14}$ showed that dogs under general barbiturate anaesthesia were able to compensate for pulmonary artery occlusion and to maintain systemic blood pressure 27 per cent better than dogs under spinal anaesthesia. Their work indicates that there are circulatory reflexes, mediated via the sympathetic outflow, which increase the ability of the right ventricle to overcome obstruction to flow in the pulmonary artery. This would offset any tendency to a diminution in cardiac output, thereby helping to maintain systemic blood pressure.

Under spinal anaesthesia these reflexes are obtunded. Additional factors adversely affecting circulatory compensation under spinal anaesthesia are the low peripheral resistance and reduced venous return to the heart.

It appears unlikely that arteriolar and capillary dilatation during flushing in those areas not affected by the spinal sympathetic blockade would be an important factor in precipitating circulatory decompensation. Haddy and colleagues ${ }^{15}$ have shown that the fall in peripheral resistance produced by serotonin infusion is compensated by an accompanying arterial and venous constriction, resulting in little over-all change in vascular resistance. This would correspond to the patchy cyanosis of Thorson's Stage III.

\section{Fibrotic Heart Lesions}

In patients with long-standing disease a further complicating factor may be introduced. The contractual efficiency and output of the right ventricle may be diminished by the development of fibrotic heart lesions.

Acquired cardiac lesions are commonly found with advanced carcinoid disease and Tables III and IV show the relevant autopsy findings in 46 cases investigated by Thorson. ${ }^{1}$ It is apparent that the fibrotic lesions affect mainly the right side of the heart and may be related to the stress and strain thrown on the right ventricle and atrium during flushing episodes. As the disease progresses cardiac efficiency diminishes and finally heart failure supervenes.

TABLE III

Cardiac Lesions in 46 Cases of Carcinoid Disease

\begin{tabular}{lcc}
\hline \multicolumn{1}{c}{ Lesion } & $\begin{array}{c}\text { Right } \\
\text { heart }\end{array}$ & $\begin{array}{c}\text { Left } \\
\text { heart }\end{array}$ \\
\hline Myocardial hypertrophy or dilatation & 27 & 9 \\
Endocardial fibrosis & 23 & 6 \\
Valvular fibrosis & 70 & 19 \\
Valvular fibrosis with dysfunction & 47 & - \\
\hline
\end{tabular}


TABLE IV

ANalysis of ValuUlar Lesions

\begin{tabular}{lccll}
\hline \multicolumn{1}{c}{ Valve } & $\begin{array}{c}\text { Fibrosis } \\
\text { only }\end{array}$ & Stenosis & Insuff. & Both \\
\hline Pulmonary & 6 & 24 & 1 & 3 \\
Tricuspid & 17 & 10 & 7 & 2 \\
Mitral & 14 & - & - & - \\
Aortic & 5 & - & - & - \\
\hline
\end{tabular}

Thus under spinal anaesthesia there can arise the situation of an inefficient heart trying to maintain an effective circulation in the face of a constricted pulmonary vascular bed and a low peripheral resistance. With general anaesthesia the chances of adequate compensation are improved as the delferious effects of a low peripheral resistance and the ablation of sympathetic reflexes are not present.

\section{Anaesthetic Management}

It is apparent that an important factor in the management of these patients is the prevention of circulatory decompensation precipitated by a sudden increase in circulating serotonin. The stimulus for initiating this release of serotonin from the tumour cells may be emotional stress, hypotension, or palpation of the tumour and metastases.

The patient should be adequately premedicated, both psychologically and chemically, prior to surgery. Induction of anaesthesia must be unhurried, and take place in a quiet, relaxed atmosphere, so that hypotension and excitement are avoided.

Gentleness and finesse by the surgeon when palpating the tumour, combined with adequate exposure and good muscular relaxation, are also mandatory.

Anaesthetic agents and techniques that may produce hypotension, such as spinal and epidural block and Fluothane, are contraindicated. Care must be exercised when moving the patient and sudden alterations in the degree of tilt of the operating table avoided. Sudden tilting of the anaesthetized patient may produce severe hypotension due to loss of vasomotor control.

To avoid throwing undue strain on the myocardium, blood replacement must be prompt and adequate, but care /should be taken not to overburden the circulation with excessive fluid.

If administration of a vasopressor is necessary to combat hypotension, the use of Noradrenaline (Levophed) is contraindicated as there is evidence that it may stimulate release of serotonin. ${ }^{16,17}$

\section{SUMMARY}

During the course of anaesthesia, in patients with malignant carcinoid disease, sudden episodes of hypotension may occur. These are apparently due to the failure of compensatory mechanisms in the cardiovascular system to adjust rapidly to the effects of sudden serotonin release. 
A contributory cause, in long-standing disease, is the development of fibrotic lesions in the heart which impair myocardial efficiency and lead, eventually, to cardiac failure.

The anaesthetist has a vital role in the maintenance of circulatory homeostasis. He must choose an anaesthetic technique that does not stimulate release of serotonin into the circulation and interferes as little as possible with circulatory physiology. By intelligent anticipation, careful management and strict adherence to well-established anaesthetic principles he can greatly assist a tired and overstrained cardiovascular system in combating the stressful effects of hyperserotoninaemia.

\section{RÉSUMÉ}

Au cours de l'anesthésie, chez les malades porteurs de la maladie carcinoïde maligne, il peut survenir soudainement des épisodes d'hypotension. Selon toute apparence, cela surviendrait à cause de l'absence, dans le système cardiovassculaire, de mécanismes compensateurs capables de réagir rapidement à la libération soudaine de sérotonine.

Dans les cas où la maladie existe depuis longtemps, il existe une autre cause qui pourrait contribuer à cette hypotension, c'est le développement de lésions fibreuses dans le cœur, lésions qui entravant l'efficacité du myocarde et, éventuellement, peuvent conduire à la défaillance cardiaque. Un facteur important dans le soin de ses malades, c'est la prévention de la décompensation circulatoire occasionnée par l'augmentation soudaine de la sérotonine circulante. Le stimulus pour déclencher la libération de sérotonine à partir des cellules tumorales peut consister en une agression émotive, une hypotension ou la palpation de la tumeur ou des métastases.

En conséquence, avant la chirurgie, le malade doit être prémédiqué adéquatement, psychologiquement et chimiquement. L'induction de l'anesthésie doit être faite sans précipitation et se faire dans un endroit sans bruit, dans une atmosphère de détente de façon à éviter l'excitation et l'hypotension. Les agents anesthésiques et les techniques qui sont susceptibles de provoquer de l'hypotension sont contreindiqués; ainsi, en est-il de la rachianesthésie, du blocage épidural et du fluothane. Il faut déplacer le malade avec soins et éviter les changements subits dans l'inclinaison de la table d'opération.

L'anesthésiste joue un rôle vital dans le maintien de l'équilibre circulatoire. Il faut choisir une technique anesthésique qui ne favorise pas la libération de sérotonine dans la circulation et qui nuit le moins possible à la physiologie circulatoire. S'il fait preuve d'une clairvoyance intelligente, s'il prodigue des soins minutieux et s'il s'en tient strictement aux principes anesthésiques bien établis, l'anesthésiste peut aider considérablement un système cardiovasculaire fatigué et surmené à lutter contre les effets stressants de l'hypersérotoninémie.

\section{REFERENCES}

1. Tronson, A. Studies on Carcinoid Disease. Acta Med. Scand. 161: Suppl. 334 (1958).

2. PAGE, I. H. Serotonin (5-Hydroxytryptamine); the Last Four Years. Physiol. Rev. 38: 277 (1958).

3. HADDY, F. J. Serotonin and the Vascular System. Angiology 11: 21 (1960). 
4. Thorson, A. Hemodynamic Changes during "Flush" in Carcinoidosis. Am. Heart J: 52: $444(1956)$.

5. Bionck, G.; Axen, D.; \& Thorson, A. Unusual Cyanosis in a Boy with Congenital Pulmonary Stenosis and Tricuspid Insufficiency. Fatal Outcome after Angiocardiography. Am. Heart J. 44: 143 (1952).

6. Thorson, A.; Bionck, G.; Bjorkman, G.; \& Waldenstrom, J. Malignant Carcinoid of the Small Intestine with Metastases to the Liver, Valvular Disease of the Right Side of the Heart (Pulmonary Stenosis and Triouspid Regurgitation without Septal Defects), Peripheral Vasomotor Symptoms, Bronchoconstriction, and an Unusual Type of Cyanosis: A Clinical and Pathologic Syndrome. Am. Heart J. 47 : 795 (1954).

7. WaUGH, J. M. Personal communication.

8. Hand, A. M.; McCormack, W. F.; \& Lumb, G. Malignant Carcinoid Tumor. A Case Report with Discussion of Systemic Manifestations. Am. J. Clin. Path. 30: 47 (1958).

9. Gamitis, R. S., \& Schrember, W. Malignant Clarcinoid Syndrome and Latest Concepts in Serotonin Metabolism. Am. J. Surg. 99: 84 (1960).

10. Price, H. L. General Anesthesia and Circulatory Homeostasis. Physiol. Revs. 40: 187 (1960).

11. Bacditghi, V., \& Ferrari, V. Risposte Emopressorie Sistemiche e Polmonari all Serotonina (5-Idrossitriptamina) nell'Uomo Folia Card. 14: 7 (1955).

12. Aviado, D. M. The Pharmacology of the Pulmonary Circulation. Pharmacol. Revs. 12: 159 (1960).

13. Taquini, A. C., \& Aviado, D. M. Reflex Stimulation of the Heart Induced by Partial Occlusion of the Pulmonary Artery. Am. J. Physiol. 200: 647 (1961).

14. Guyton, A. C.; Lindsey, A. W.; \& Gilluly, J. J. The Limits of Right Ventricular Compensation Following Acute Increase, in Pulmonary Circulatory Resistance. Circul. Res. 2: 326 (1954).

15. Haddy, F. J.; Fleishman, M.; \& Emanuer, D. A. Effect of Epinephrine, Norepinephrine and Serotonin upon Systemic Small and Large Vessel Resistances. Circul. Res. 5: 247 (1957).

16. Stacey, R. S. Malignant Carcinoid Tumours. Proc. Roy. Soc. Med. 50: 40 (1957).

17. Schneckloth, R.; Page, I. H.; Del Greco, F.; \& Corcoran, A. C. Effects of Serotonin Antagonists in Normal Subjects and Patients with Carcinoid Tumours. Circulation 16: 523 (1957).

18. Jones, W. P. G. Serotonin and the Carcinoid Syndrome. Canad. Anaesth. Soc. J. 6: 130 (1959). 